\title{
Comorbidity: From a Confounder in Longitudinal Clinical Research to the Main Issue in Population Management
}

\author{
Mary E. Charlson ${ }^{a}$ Martin T. Wells ${ }^{b}$ \\ ${ }^{a}$ Department of Medicine, Weill Cornell Medicine, New York, NY, USA; ${ }^{b}$ Department of Statistics and Data Science, \\ Ithaca, NY, USA
}

In his recent editorial "Forty Years of Clinimetrics," Fava eloquently summarized the contribution of clinimetrics to moving clinical science from a focus on diagnosis and treatment of a single disease in isolation to the understanding that any illness occurs in a person whose life context, including their individual, family, community and environmental stresses and supports, immeasurably impacts their prognosis, overall physical and psychosocial well-being and outcomes [1]. Moreover, with any specific illness, an individual's symptoms and severity, progression of illness, response to treatment and quality of life is complex and often not a linear function of a specific treatment [1].

Alvan Feinstein coined the term "clinimetrics" to define a new set of methods and approaches to measure clinical phenomena $[2,3]$. Under the broad umbrella of clinimetrics, he developed sets of principles relevant to many issues, among them assessment of prognosis [4]. In vintage form (taking no prisoners), Feinstein argued: "There never has been and never will be a natural history population. This belief may have been valid for agricultural plots, brewery vats and fruit flies, but the belief is not true for a free-living population. The first step for scientists who want to investigate prognosis, therefore is to recognize that we can study clinical course, but not natural

Karger@karger.com www.karger.com/pps

Karger"
(C) 2022 The Author(s)

Published by S. Karger AG, Basel

This is an Open Access article licensed under the Creative Commons Attribution-NonCommercial-4.0 International License (CC BY-NC) (http://www.karger.com/Services/OpenAccessLicense), applicable to the online version of the article only. Usage and distribution for commercial purposes requires written permission. history" [4]. At Yale, in his inimitable fashion, Feinstein went on to describe many new clinimetric methods and principles, among them the concept of comorbidity which he defined as "any distinct additional clinical entity that has existed or that may occur during the clinical course of a disease that is under study" and "that has the potential not only to impact a patient's prognosis, but also to alter their therapeutic plans and outcomes" [5]. This includes conditions that can occur as lasting, but unintended consequence of treatment, that is, iatrogenic comorbidity [6]. Feinstein and Kaplan [7] subsequently developed the first method of assessing comorbidity.

Building on the lessons learned at Yale, the Charlson comorbidity index was subsequently developed to provide an empirically based weighted measure of the prognostic impact of chronic conditions on long-term mortality [8]. Over the ensuing years, the Charlson comorbidity index has maintained its usefulness as a predictor of longterm mortality and has been employed in thousands of studies and has over 36,000 citations in Scopus. There are several likely reasons for its durability. It was developed in a population of hospitalized medical patients, controlling for age and the physician's assessment of illness severity at the time of admission, to predict 1-year mortality. It was then validated in a completely separate popula- 
tion of breast cancer patients to predict 10-year mortality from diseases other than breast cancer [8]. The very different populations and the different follow-up intervals are likely key to its generalizability and its endurance over time. Before turning to the critical importance of comorbidity in the current era, the methodological issues in design of such measures of comorbidity and how they have been used (or not) will be reviewed.

\section{Methodological Issues Critical in the Design of Comorbidity (i.e., Multiple Chronic Disease) Measures}

\section{The Development and Validation Populations}

A number of studies that created new measures of comorbidity have developed them in one population and then validated it in a similar population - over a similar followup interval. Often, a given population has been divided into a split sample, with testing/development in one part of the sample (often selected at random) and validation in the other. In these circumstances, the predictions are likely to be largely concordant. Often, the validation of the measure will be good in the split sample but will perform considerably less well when applied to a different population [9]. In machine learning, this is called data drift - when an unexpected difference between the training and testing data violates the assumption that past predicts present [10].

For those reasons, it's preferable for such measures to be validated in a completely different population - over different time frames, in different geographic locations or in different clinical settings $[11,12]$. This independent validation population is critical, because any validation population woven too tightly to the testing population is likely to drastically limit its generalizability [13]. Patients drawn from one population may differ from another population in ways that are not obvious at the outset. If the measure has enduring predictive validity, the specific outcome rates in each strata or rank of a predictive index may differ, but the gradients should be quite similar, that is, the index should discriminate between those with and without the outcome of interest in a graded fashion [14].

\section{Numbers of Candidate Conditions}

Some efforts to assess comorbidity have included large numbers of conditions which may increase the prediction of the initial model; however, the use of a large number of conditions often radically reduces the predictive ability of the model when applied to another population [9]. Moreover, taking individual conditions, with or without weights, and testing them one by one for whether they should be included in a measure also tends to vastly overfit the models; again when the models are applied, their performance and generalizability drop dramatically [9].

\section{Generic versus Disease-Specific Measures}

Some measures have been created to assess comorbidity relevant to one specific index disease. Yet the problem with assessing chronic conditions selected for their relevance to one disease is that it can result in many different indices relevant only to that disease (i.e., acute myelogenous leukemia, stem cell transplant, rheumatoid arthritis, etc.). If that is done for each chronic condition, there could be thousands of condition-specific comorbidity measures, which would not extrapolate across populations, resulting in confusion rather than clarity. It would be like adjusting age for average length of life for each specific county in the USA (rather than for the population as a whole), drastically limiting the ability to perform cross-population comparisons. Thus, such disease-specific measures usually result in a complete lack of comparability between studies.

\section{The Elements in Comorbidity Assessments}

Some have used a count of the total number of diseases as the framework for measuring comorbidity. But which conditions of the 69,000 ICD-10-CM codes should be counted? There is no universally correct answer; it depends on the rationale. The overarching question is: disease counts for what purpose? Tennis elbow, gout or hearing impairment could all be classified as diseases, but they do not impact survival, although they may impact other patient outcomes. In addition, there is little evidence that such counts are reproducible or have a biological basis [15]. Others have suggested a focus on combinations of chronic conditions. However, one study of 32.2 million Medicare recipients found more than 23.5 million disease combinations; split into three groups by expenditure, the highest cost group which had $32 \%$ of the patients still had more than 2 million disease combinations [16]. Total or specific medications have also been used to assess the burden of disease with similar issues: what should be counted singly or in combination? [17]. In addition, medication lists often change and may reflect drugs that were prescribed, but may not be current, or the patient may not be taking them.

The term "multimorbidity" - which at times has been used interchangeably with comorbidity - has been defined by many different criteria - most commonly as two or more conditions [18], but also as one of 40 chronic diseases [19], one of 918 ICD-10 disease groups grouped 
into 60 categories [20], two of 28 diseases [21], treatment with multiple medications [17], impaired quality of life or function [22] and/or physical and mental disorders [19]. The lack of a standard definition vastly complicates the interpretation and use of multimorbidity [18, 23-25]. Another complicating issue is that 17 core outcomes have been recommended for multimorbidity research including quality of life, patient impact and behavior, physical activity and function, mental health, mortality and health system measures [26]. Some of the studies cited in a review of interventions targeted at multimorbidity did not use multimorbidity as an inclusion criterion [25]. Thus, when a randomized controlled trial (RCT) of a practicelevel patient-centered intervention designed for patients with multimorbidity did not significantly improve quality of life [27], the critique was that the definition for inclusion was based on the number of diagnoses alone and should have included frailty and other criteria [28]. Some studies have used cluster analysis and network to evaluate patterns of multimorbidity across populations, using different definitions of included diseases, variable numbers of disease categories and clusters of multimorbidity, making them difficult to interpret or compare [20, 29-31].

\section{The Outcomes}

Finally, it's important to note that the Charlson comorbidity index was designed specifically to predict long-term mortality, not all outcomes [8]. Often it has been tested for its ability to predict other outcomes, and its performance, as would be expected, is variable; however, an index designed to predict survival cannot not be assumed to predict function, quality of life, hospitalizations, readmissions, or health care costs. Moreover, the Charlson comorbidity index was not designed to predict an outcome for an individual patient but was designed to predict mortality from chronic diseases in a group of patients and control for the confounding prognostic impact of multiple chronic diseases on outcomes. Predicting outcomes of individuals requires an understanding of what drives heterogeneity in individual outcomes, including their biological, clinical, psychosocial and environmental profile [32].

\section{Comorbidity Measures Rarely Used as an Effect Modifier or Determinant of Treatment Heterogeneity}

At the time when the Charlson comorbidity index was developed, the scientific focus was on measuring comorbidity in order to control for the confounding impact of prognostically significant multiple chronic diseases on long-term mortality for patients in observational or interventional studies of specific acute or chronic conditions. That was critically important because patients with significant comorbidity had often been excluded from observational studies and clinical trials, because their presence could bias outcomes. Over the ensuing decades, although the Charlson comorbidity index has been used in thousands of studies, patients with comorbid disease were often still excluded from studies, especially clinical trials. One review of RCTs published between 1994 and 2006 showed that patients with comorbidity were excluded from $65 \%$ of RCTs [33], while another review of 284 RCTs in high-impact journals over 4 multi-year intervals between 1995 and 2010 found that only $2.1 \%$ of RCTs explicitly included patients with multiple chronic diseases [34]. In addition, there is often ambiguity in publications about how comorbidity was addressed with regard to eligibility criteria (if at all) [35].

Among the RCTs that did not exclude patients with comorbidity, only a few evaluated whether comorbidity was an effect modifier or whether it resulted in heterogeneous treatment responses. A review of 161 RCTs of pharmacological treatments for diabetes, heart failure, chronic obstructive disease or stroke between 1944 and 2009 showed that only $3.1 \%$ evaluated whether comorbid disease was an effect modifier, and only $0.6 \%$ considered the impact of comorbidity on treatment heterogeneity [36]. The failure to examine effect modification or treatment heterogeneity has tremendous implications in the era of evidence-based medicine [37] whose key objective is to harness the results of randomized clinical trials to develop disease-specific recommendations - resulting in hundreds of clinical practice guidelines [23].

As a result, almost none of the disease-specific guidelines address the problems faced by patients with multiple chronic conditions, and most guidelines do not address whether they are even applicable to patients with significant comorbidity $[24,38,39]$. While it is recognized that using the guidelines for medication management for achieving disease-specific targets (i.e., hemoglobin $\mathrm{A}_{1 \mathrm{c}}$ or blood pressure) in older patients with multiple chronic diseases can lead to untoward effects, such consequences also occur in younger patients [40]. Since at least $33 \%$ of patients globally have more than one chronic condition [41] and $45 \%$ of primary care patients in the USA have 3 or more conditions [42], this poses major challenges for the validity of the systematic application of clinical practice guidelines. In addition, studies have made it clear that patients with multiple chronic diseases cannot be man- 
aged according to disease-specific guidelines [43]. As an example, in one shift in a hospital, physicians saw 18 patients with 44 diagnoses, and the associated guidelines came to 3,679 pages, which at 2 min per page would require $122 \mathrm{~h}$ to read [44]. Similarly in primary care, $3.5 \mathrm{~h}$ per day would be required to follow practice guidelines for 10 common chronic diseases, and the burden of application to specific patients is equally unmanageable [45-47]. In summary, comorbidity clearly may modify the effect of treatment, may be a determinant of treatment heterogeneity and often is ignored in studies that measure it, leading to calls for explicit incorporation of comorbidity in guidelines [48].

\section{Moving to Comorbidity as the Focus}

The Charlson comorbidity index was designed to control for the confounding influence of comorbidity on survival, but over the ensuing decades, another critical series of questions have emerged, because high comorbidity also has an adverse impact on physical and mental health, disability, quality of life and health care utilization [4954]. The focus on comorbidity sharpened once it was realized that the health care utilization dramatically increased in those with multiple chronic diseases [55].

Yet, explicit studies of patients with multiple chronic diseases are rare, and as a result, there is extremely limited knowledge about the best strategies for managing such patients. Many studies that ostensibly focused on patients with multiple chronic diseases have actually focused on patients who had prior high health care costs or hospitalizations ("super-utilizers"). The Congressional Budget Office analysis has shown that these strategies do not work, because both prior health care costs and prior hospitalization overestimate subsequent health care utilization [56]. The Congressional Budget Office also found that the presence of multiple chronic conditions was the most stable predictor of high costs in Medicare beneficiaries [56]. A study of 4,774 individuals out of a population of 214,000 who had $\geq 3$ hospitalizations (or $>2$ hospitalizations with a serious mental illness) over a 12-month period reinforced this finding [57]. It showed that only $28 \%$ of patients remained "super-utilizers" at the end of the first year and only $14 \%$ at the end of the second year [57]. Thus, for most patients utilization decreased sharply, but for those patients who had continued high health care use, the majority had multiple chronic diseases [57]. Nonetheless, high utilization (hospitalization, emergency visits, total costs) are still often used as a proxy definition to define patients in need of attention and intervention, and this definition drives most of the proprietary risk models [58]. The issues, especially racial bias, with proprietary algorithms employed to manage the health of populations focused on cost as a proxy for high need have been recently elegantly documented [59].

More recently the term "complex patients" has come into vogue as another method of defining high-risk patients, but there is limited agreement on the definition [60]. A recent review of articles between 2000 and 2018 had 90 separate definitions of a complex patient population, heavily weighted to high health care utilization [60]. One model of complexity segmented 611,245 Medicare patients who had the highest $10 \%$ of costs hierarchically into six groups: (1) dialysis and disability; (2) frail elderly; (3) those $>65$ with one or more chronic illnesses from 29 clusters of disease of which 9 classified as complex and 20 noncomplex classified into 3 separate groups as: (3a) major complex: $\geq 2$ complex conditions or $\geq 6$ noncomplex conditions; (3b) minor complex conditions: 1 complex condition and $<6$ noncomplex conditions; (3c) simple chronic: 1-5 noncomplex and (6) relatively healthy [61]. Surprisingly there was only a USD 10,000 annual cost difference between the lowest and highest complexity segments (USD 54,183 vs. 71,210) [61]. This definition was used by the National Academy of Medicine in their evaluation of high need patients [62]. An evaluation of 20 different definitions of complexity, using various cut points for complex and noncomplex, emergency department visits, hospitalization and prior high costs demonstrates that across all definitions, a large percentage of patients did not have persistent high cost [63]. This has been found in other populations [64].

There are many papers stressing that multiple chronic diseases are a "complex, unpredictable, intractable" problem and some strategies to address the issue [47, 65-69]. The results of the few interventions to improve care for patients with multiple chronic disease have been "mixed, and when effective, modest at best" [65]. Partly as a result, there is more emphasis on moving away from cost or utilization as the key criteria for identifying and intervening on patients with multiple chronic disease [70].

Previously, we have shown that disease management programs likely could not achieve significant cost savings because most enrolled patients with chronic illness had a low burden of comorbidity [71]. Case management, care coordination and other similar initiatives that ostensibly focused on patients with chronic disease including Chronic Care Clinics, the Chronic Care Model, Medicare Coordinated Care, the Guided Care Model and GRACE 
used a variety of eligibility criteria but rarely explicitly focused on patients with multiple chronic diseases [72-84]. Most would agree that these initiatives have elements that are important to address the needs of patients with multiple chronic conditions. Yet, for the most part, they did not improve outcomes or reduce utilization because they did not target the right patients.

Interventions in patients with multiple chronic disease have to accurately identify the small proportion of patients who have the worst outcomes and leverage that knowledge to create novel interventions, building on those such as chronic disease self-management that clearly work $[85,86]$. If not targeted on the highest risk patients, the intervention will cost more than it will save, because increased resources will be devoted to lower risk patients who do not need them $[78,87]$. Using the Charlson comorbidity index, depending on the specific population and the criteria, can identify between 6 and $20 \%$ of adults have prognostically significant multiple chronic diseases $[88,89]$.

This is the challenge of comorbidity in this decade. Most agree that patient activation, empowerment and engagement, that is grounded in the realities of an individual's context and support system, are key to improving health in patients with significant comorbidity [90-93]. Average results from RCTs cannot be applied to patients with high comorbidity because of the tremendous heterogeneity of the patients [94]. Interventions need to be tailored and translated to a model of personalized medicine that integrates social, psychological, ecological and basic biological information with clinical experience to tailor the best approach [32]. Experienced clinicians consider the individual patient's risk, in the context of other chronic diseases and their likely impact on response to treatment along with the knowledge from treating other patients. The focus on patients with significant comorbidity requires a shift from evidence-based medicine, in which treatment is standardized based on the average results of RCTs, to medicine-based evidence, in which individual variability in response to treatment is a critical issue [9598]. The importance of medicine-based experience and evidence is critical to identifying the optimal strategies for the care of patients with significant comorbidity [99].

\section{Conflict of Interest Statement}

M.E.C.: Cornell University has filed a patent for the use of the enhanced comorbidity index to predict future costs.

M.T.W. has no conflict of interest.

\section{Funding Sources}

M.E.C. reports the following grants: PCORI (IHS-2017C3-8923), NHLBI (T32 HL135465-01A) and NIMHD (5T37MD014220-02), and M.T.W. reports NIH grant U19A11143, PCORI (IHS2017C3-8923) and Cornell's Center for the Social Sciences project on Algorithms, Big Data and Inequality, outside of the submitted work and unrelated to the preparation of the manuscript.

\section{Author Contributions}

All the authors provided a substantial contribution to the conception of the work, and all the authors drafted and finalized the paper.

\section{References}

1 Fava GA. Forty years of clinimetrics. Psychother Psychosom. 2022;91:1-7.

2 Feinstein AR. T. Duckett Jones memorial lecture. The Jones criteria and the challenges of clinimetrics. Circulation. 1982 Jul;66(1):1-5.

3 Feinstein AR. An additional basic science for clinical medicine. IV. The development of clinimetrics. Ann Intern Med. 1983 Dec; 99(6):843-8.

4 Feinstein AR. Clinical biostatistics. XIV. The purposes of prognostic stratification. Clin Pharmacol Ther. 1972 Mar-Apr;13(2):28597.

5 Feinstein AR. The pre-therapeutic classification of co-morbidity in chronic disease. J Chronic Dis. 1970 Dec;23(7):455-68.

6 Fava GA, Rafanelli C. Iatrogenic factors in psychopathology. Psychother Psychosom. 2019;88(3):129-40.
7 Kaplan MH, Feinstein AR. The importance of classifying initial co-morbidity in evaluating the outcome of diabetes mellitus. J Chronic Dis. 1974 Sep;27(7-8):387-404.

8 Charlson ME, Pompei P, Ales KL, MacKenzie CR. A new method of classifying prognostic comorbidity in longitudinal studies: development and validation. J Chronic Dis. 1987; 40(5):373-83.

9 Harrell FE Jr, Lee KL, Califf RM, Pryor DB, Rosati RA. Regression modelling strategies for improved prognostic prediction. Stat Med. 1984;3(2):143-52.

10 Sarantitis G. Data shift in machine learning: what is it and how to detect it. 2021 Jun 24 [updated 2021]. Available from: https://gsarantitis/wordpress.com/2020/04/16/datashift-in-machine-leanriing-what-it-is-andhow-to-detect-it.
11 Toll DB, Janssen KJ, Vergouwe Y, Moons KG Validation, updating and impact of clinical prediction rules: a review. J Clin Epidemiol. 2008 Nov;61(11):1085-94.

12 Moons KG, Kengne AP, Grobbee DE, Royston P, Vergouwe Y, Altman DG, et al. Risk prediction models. II. External validation, model updating, and impact assessment. Heart. 2012 May;98(9):691-8.

13 Siontis GC, Tzoulaki I, Castaldi PJ, Ioannidis JP. External validation of new risk prediction models is infrequent and reveals worse prognostic discrimination. J Clin Epidemiol. 2015 Jan;68(1):25-34.

14 Harrell FE Jr, Lee KL, Mark DB. Multivariable prognostic models: issues in developing models, evaluating assumptions and adequacy, and measuring and reducing errors. Stat Med. 1996 Feb;15(4):361-87. 
15 de Groot V, Beckerman H, Lankhorst GJ, Bouter LM. How to measure comorbidity. a critical review of available methods. J Clin Epidemiol. 2003 Mar;56(3):221-9.

16 Sorace J, Wong HH, Worrall C, Kelman J, Saneinejad S, MaCurdy T. The complexity of disease combinations in the Medicare population. Popul Health Manag. 2011 Aug;14(4): 161-6.

17 Sasseville M, Smith SM, Freyne L, McDowell R, Boland F, Fortin M, et al. Predicting poorer health outcomes in older community-dwelling patients with multimorbidity: prospective cohort study assessing the accuracy of different multimorbidity definitions. BMJ Open. 2019 Jan;9(1): e023919.

18 Weiss CO, Varadhan R, Puhan MA, Vickers A, Bandeen-Roche K, Boyd CM, et al. Multimorbidity and evidence generation. J Gen Intern Med. 2014;29(4):653-60.

19 Barnett K, Mercer SW, Norbury M, Watt G, Wyke S, Guthrie B. Epidemiology of multimorbidity and implications for health care, research, and medical education: a cross-sectional study. Lancet. 2012 Apr;380(9836):3743.

20 Calderon-Larranaga A, Vetrano DL, Onder G, Gimeno-Feliu LA, Coscollar-Santaliestra $\mathrm{C}$, Carfi A, et al. Assessing and measuring chronic multimorbidity in the older population: a proposal for its operationalization. J Gerontol A Biol Sci Med Sci. 2017 Oct;72(10): 1417-23.

21 van Oostrom SH, Picavet HS, de Bruin SR, Stirbu I, Korevaar JC, Schellevis FG, et al. Multimorbidity of chronic diseases and health care utilization in general practice. BMC Fam Pract. 2014 Apr; 15:61.

22 Smith SM, Wallace E, Clyne B, Boland F, For tin M. Interventions for improving outcomes in patients with multimorbidity in primary care and community setting: a systematic review. Syst Rev. 2021 Mar;10(1):271.

23 Maciejewski ML, Bayliss EA. Approaches to comparative effectiveness research in multimorbid populations. Med Care. 2014 Mar;52 Suppl 3:S23-30

24 Uhlig K, Leff B, Kent D, Dy S, Brunnhuber K, Burgers JS, et al. A framework for crafting clinical practice guidelines that are relevant to the care and management of people with multimorbidity. J Gen Intern Med. 2014 Apr; 29(4):670-9.

25 Smith SM, Wallace E, O'Dowd T, Fortin M. Interventions for improving outcomes in patients with multimorbidity in primary care and community settings. Cochrane Database Syst Rev. 2016 Mar;3:CD006560.

26 Smith SM, Wallace E, Salisbury C, Sasseville M, Bayliss E, Fortin M. A core outcome set for multimorbidity research (COSmm). Ann Fam Med. 2018 Mar;16(2):132-8

27 Salisbury C, Man MS, Bower P, Guthrie B, Chaplin K, Gaunt DM, et al. Management of multimorbidity using a patient-centred care model: a pragmatic cluster-randomised trial of the 3D approach. Lancet. 2018 Jul; 392(10141):41-50

28 Marengoni A, Vetrano DL, Calderón-Larrañaga $\mathrm{A}$, Onder $\mathrm{G}$. Multimorbidity and patient-centred care in the 3D trial. Lancet. 2019 Jan;393(10167):127-8.

29 Prados-Torres A, Calderón-Larrañaga A, Hancco-Saavedra J, Poblador-Plou B, van den Akker M. Multimorbidity patterns: a systematic review. J Clin Epidemiol. 2014 Mar;67(3): 254-66.

30 Vetrano DL, Roso-Llorach A, Fernandez S, Guisado-Clavero M, Violan C, Onder G, et al. Twelve-year clinical trajectories of multimorbidity in a population of older adults. Nat Commun. 2020 Jun;11(1):3223.

31 Goh KI, Cusick ME, Valle D, Childs B, Vidal M, Barabási AL. The human disease network. Proc Natl Acad Sci U S A. 2007;104(21):868590.

32 Horwitz RI, Charlson ME, Singer BH. Medicine based evidence and personalized care of patients. Eur J Clin Invest. 2018 Jul;48(7): e12945.

33 van Spall HG, Toren A, Kiss A, Fowler RA. Eligibility criteria of randomized controlled trials published in high-impact general medical journals: a systematic sampling review. JAMA. 2007 Mar;297(11):1233-40.

34 Jadad AR, To MJ, Emara M, Jones J. Consideration of multiple chronic diseases in randomized controlled trials. JAMA. 2011 Dec; 306(24):2670-2.

35 Fortin M, Dionne J, Pinho G, Gignac J, Almirall J, Lapointe L. Randomized controlled trials: do they have external validity for patients with multiple comorbidities? Ann Fam Med. 2006 Mar-Apr;4(2):104-8

36 Boyd CM, Vollenweider D, Puhan MA. Informing evidence-based decision-making for patients with comorbidity: availability of necessary information in clinical trials for chronic diseases. PLoS One. 2012;7(8):e41601.

37 Institute of Medicine. Crossing the quality chasm: a new system for the 21st Century. Washington: Institute of Medicine; 2001.

38 Lugtenberg M, Burgers JS, Clancy C, Westert GP, Schneider EC. Current guidelines have limited applicability to patients with comorbid conditions: a systematic analysis of evidence-based guidelines. PLoS One. 2011; 6(10):e25987.

39 Boyd CM, Kent DM. Evidence-based medicine and the hard problem of multimorbidity. J Gen Intern Med. 2014 Apr;29(4):552-3.

40 Tinetti ME, Green AR, Ouellet J, Rich MW, Boyd C. Caring for patients with multiple chronic conditions. Ann Intern Med. 2019 Feb;170(3):199-200.

41 Hajat C, Stein E. The global burden of multiple chronic conditions: a narrative review. Prev Med Rep. 2018 Oct;12:284-93.

42 Ornstein SM, Nietert PJ, Jenkins RG, Litvin $\mathrm{CB}$. The prevalence of chronic diseases and multimorbidity in primary care practice: a PPRNet report. J Am Board Fam Med. 2013 Sep-Oct;26(5):518-24.
43 Tinetti ME, Bogardus ST Jr, Agostini JV. Potential pitfalls of disease-specific guidelines for patients with multiple conditions. N Engl J Med. 2004 Dec;351(27):2870-4.

44 Allen D, Harkins KJ. Too much guidance? Lancet. 2005 May;365(9473):1768.

45 Ostbye T, Yarnall KS, Krause KM, Pollak KI, Gradison M, Michener JL. Is there time for management of patients with chronic diseases in primary care? Ann Fam Med. 2005 MayJune;3(3):209-14.

46 Buffel du Vaure C, Ravaud P, Baron G, Barnes C, Gilberg S, Boutron I. Potential workload in applying clinical practice guidelines for patients with chronic conditions and multimorbidity: a systematic analysis. BMJ Open. 2016 Mar;6(3):e010119.

47 Leroy L, Bayliss E, Domino M, Miller BF, Rust $\mathrm{G}$, Gerteis J, et al. The agency for healthcare research and quality multiple chronic conditions research network: overview of research contributions and future priorities. Med Care. 2014 Mar;52 Suppl 3:S15-22.

48 Arnett DK, Goodman RA, Halperin JL, Anderson JL, Parekh AK, Zoghbi WA. AHA/ ACC/HHS strategies to enhance application of clinical practice guidelines in patients with cardiovascular disease and comorbid conditions: from the American Heart Association, American College of Cardiology, and US Department of Health and Human Services. Am Coll Cardiol. 2014 Oct;64(17):1851-6.

49 Bayliss EA, Bayliss MS, Ware JE Jr, Steiner JF. Predicting declines in physical function in persons with multiple chronic medical conditions: what we can learn from the medical problem list. Health Qual Life Outcomes. 2004 Sep;2:47.

50 Gabbe BJ, Harrison JE, Lyons RA, Edwards ER, Cameron PA; Victorian orthopaedic trauma outcomes registry. Comparison of measures of comorbidity for predicting disability 12-months post-injury. BMC Health Serv Res. 2013 Jan;13:30.

51 Walker AE. Multiple chronic diseases and quality of life: patterns emerging from a large national sample, Australia. Chronic Illn. 2007 Sep;3(3):202-18.

52 Marengoni A, von Strauss E, Rizzuto D, Winblad B, Fratiglioni L. The impact of chronic multimorbidity and disability on functional decline and survival in elderly persons. A community-based, longitudinal study. J Intern Med. 2009 Feb;265(2):288-95.

53 Kadam UT, Croft PR. Clinical multimorbidity and physical function in older adults: a record and health status linkage study in general practice. Fam Pract. 2007 Oct;24(5):412-

54 Wolff JL, Starfield B, Anderson G. Prevalence, expenditures, and complications of multiple chronic conditions in the elderly. Arch Intern Med. 2002 Nov;162(20):2269-76.

55 Stanton MW. The high concentration of US health care expenditures. Rockville: Agency for Health Care Research and Quality; 2006. p. 6-0060. 
56 High cost Medicare beneficiaries. Washington: Congressional Budget Office; July 2005. p. 05-3.

57 Johnson TL, Rinehart DJ, Durfee J, Brewer D, Batal H, Blum J, et al. For many patients who use large amounts of health care services, the need is intense yet temporary. Health Aff. 2015 Aug;34(8):1312-9.

58 Hileman G, Steele S. Accuracy of claims based risk scoring models. Schaumburg: Society of Actuaries; 2016.

59 Obermeyer Z, Powers B, Vogeli C, Mullainathan S. Dissecting racial bias in an algorithm used to manage the health of populations. Science. 2019 Oct;366(6464):447-53.

60 Davis AC, Osuji TA, Chen J, Lyons LJL, Gould MK. Identifying populations with complex needs: variation in approaches used to select complex patient populations. Popul Health Manag. 2021 Jun;24(3):393-402.

61 Joynt KE, Figueroa JF, Beaulieu N, Wild RC, Orav EJ, Jha AK. Segmenting high-cost Medicare patients into potentially actionable cohorts. Healthcare. 2017 Mar;5(1-2):62-7.

62 National Academy of Medicine. Effective care for high need patients. Washington: National Academy of Medicine; 2017.

63 Davis AC, Chen A, Osuji TA, Chen J, Gould MK. Defining complex patient populations: implications for population size, composition, utilization, and costs. J Gen Intern Med. 2022 Feb;37(2):351-8.

64 Johnson TL, Kaldor J, Falster MO, Sutherland K, Humphries J, Jorm LR, et al. Predictive risk modelling under different data access scenarios: who is identified as high risk and for how long? BMJ Open. 2018;8(2):e018909.

65 Bierman AS, Wang J, O'Malley PG, Moss DK. Transforming care for people with multiple chronic conditions: Agency for Healthcare Research and Quality's research agenda. Health Serv Res. 2021 Oct;56 Suppl 1:973-9.

66 Grembowski D, Schaefer J, Johnson KE, Fischer H, Moore SL, Tai-Seale M, et al. A conceptual model of the role of complexity in the care of patients with multiple chronic conditions. Med Care. 2014 Mar;52 Suppl 3:S714.

67 Parekh AK, Barton MB. The challenge of multiple comorbidity for the US health care system. JAMA. 2010 Apr;303(13):1303-4.

68 Shively MJ, Gardetto NJ, Kodiath MF, Kelly A, Smith TL, Stepnowsky C, et al. Effect of patient activation on self-management in patients with heart failure. J Cardiovasc Nurs. 2013 Jan-Feb;28(1):20-34.

69 Agency for Healthcare Research and Quality. AHRQ summit on transforming care for people living with multiple chronic conditions. 2020 Nov $17-18$

70 Savitz LA, Bayliss EA. Emerging models of care for individuals with multiple chronic conditions. Health Serv Res. 2021 Oct;56 Suppl 1:980-9.
71 Charlson M, Charlson RE, Briggs W, Hollenberg J. Can disease management target patients most likely to generate high costs? The impact of comorbidity. J Gen Intern Med. 2007 Apr;22(4):464-9.

72 Dorr DA, Wilcox A, Burns L, Brunker CP, Narus SP, Clayton PD. Implementing a multidisease chronic care model in primary care using people and technology. Dis Manag. 2006 Feb;9(1):1-15.

73 Coleman EA, Grothaus LC, Sandhu N, Wagner EH. Chronic care clinics: a randomized controlled trial of a new model of primary care for frail older adults. J Am Geriatr Soc. 1999 Jul;47(7):775-83.

74 Counsell SR, Callahan CM, Buttar AB, Clark DO, Frank KI. Geriatric Resources for Assessment and Care of Elders (GRACE): a new model of primary care for low-income seniors. J Am Geriatr Soc. 2006 Jul;54(7):113641.

75 Counsell SR, Callahan CM, Clark DO, Tu W, Buttar AB, Stump TE, et al. Geriatric care management for low-income seniors: a randomized controlled trial. JAMA. 2007 Dec; 298(22):2623-33

76 Counsell SR, Callahan CM, Tu W, Stump TE, Arling GW. Cost analysis of the Geriatric Resources for Assessment and Care of Elders care management intervention. J Am Geriatr Soc. 2009 Aug;57(8):1420-6.

77 Boult C, Reider L, Leff B, Frick KD, Boyd CM, Wolff JL, et al. The effect of guided care teams on the use of health services: results from a cluster-randomized controlled trial. Arch Intern Med. 2011 Mar;171(5):460-6.

78 Peikes D, Chen A, Schore J, Brown R. Effects of care coordination on hospitalization, quality of care, and health care expenditures among Medicare beneficiaries: 15 randomized trials. JAMA. 2009 Feb;301(6):603-18.

79 Schore J, Peikes D, Peterson G, Geralamo A, Brown R. Fourth report to Congress on the Evaluation of the Medicare Coordinated Care Demonstration. Princeton: Mathematic Policy Research Inc.; 2011 Mar. p. 6555-440.

$80 \mathrm{McCall} N$, Cromwell J, Urato C. Evaluation of Care Management for High Cost Beneficiaries (CMHCB) demonstration: Massachusetts General Hospital and Massachusetts General Physicians Organization (MGH) final report. RTI International; 2010.

81 The chronic care model: improving chronic illness care. Available from: http://www.improvingchroniccare.org.

82 Bodenheimer T, Wagner EH, Grumbach K. Improving primary care for patients with chronic illness: the chronic care model, part 2. JAMA. 2002 Oct;288(15):1909-14.

83 Cretin S, Shortell SM, Keeler EB. An evaluation of collaborative interventions to improve chronic illness care. Framework and study design. Eval Rev. 2004 Feb;28(1):28-51.

84 Coleman K, Austin BT, Brach C, Wagner EH. Evidence on the Chronic Care Model in the new millennium. Health Aff. 2009 Jan-Feb; 28(1):75-85.
85 Lorig K, Laurent DD, Plant K, Krishnan E, Ritter PL. The components of action planning and their associations with behavior and health outcomes. Chronic Illn. 2014 Mar; 10(1):50-9.

86 Lorig KR, Ritter P, Stewart AL, Sobel DS, Brown BW Jr, Bandura A, et al. Chronic disease self-management program: 2-year health status and health care utilization outcomes. Med Care. 2001 Nov;39(11):1217-23.

87 Peikes D, Brown R, Chen A, Schore J. Third report to congress on the evaluation of the Medicare coordinated care demonstration. Princeton: Mathematica Policy Research; 2008 Jan 1

88 Charlson ME, Carrozzino D, Guidi J, Patierno C. Charlson comorbidity index: a critical review of clinimetric properties. Psychother Psychosom. 2022 Jan 6;91(1):8-35.

89 Charlson ME, Wells MT, Kanna B, Dunn V, Michelen W. Medicaid managed care: how to target efforts to reduce costs. BMC Health Serv Res. 2014 Nov; 14:461.

90 Bayliss EA, Bonds DE, Boyd CM, Davis MM, Finke B, Fox MH, et al. Understanding the context of health for persons with multiple chronic conditions: moving from what is the matter to what matters. Ann Fam Med. 2014 May-Jun;12(3):260-9.

91 Vick JB, Wolff JL. A scoping review of person and family engagement in the context of multiple chronic conditions. Health Serv Res. 2021 Oct;56 Suppl 1:990-1005.

92 Tinetti ME, Basu J. Research on multiple chronic conditions: where we are and where we need to go. Med Care. 2014 Mar;52 Suppl 3:S3-6.

93 US Department of Health and Human Services. Multiple chronic conditions: a framework for education and training. Washington: US Department of Health and Human Services; 2015 Jun.

94 Deaton A, Cartwright N. Understanding and misunderstanding randomized controlled trials. Soc Sci Med. 2018 Aug;210:2-21.

95 Greenhalgh T, Howick J, Maskrey N; Evidence Based Medicine Renaissance Group. Evidence based medicine: a movement in crisis? BMJ. 2014 Jun;348:g3725.

96 Horwitz RI, Hayes-Conroy A, Caricchio R, Singer BH. From evidence based medicine to medicine based evidence. Am J Med. 2017 Nov;130(11):1246-50.

97 Wivel AE, Lapane K, Kleoudis C, Singer BH, Horwitz RI. Medicine based evidence for individualized decision making: case study of systemic lupus erythematosus. Am J Med. 2017 Nov; 130(11):1290-7.e6.

98 Feinstein AR, Horwitz RI. Problems in the "evidence" of "evidence-based medicine". Am J Med. 1997;103(6):529-35.

99 Fava GA. Evidence-based medicine was bound to fail: a report to Alvan Feinstein. J Clin Epidemiol. 2017 Apr;84:3-7. 